\title{
ОСНОВНЫЕ ПРИНЦИПЫ И ПРИЧИНЫ ВНЕДРЕНИЯ ПРЕДМЕТНО-ЯЗЫКОВОГО ИНТЕГРИРОВАННОГО ОБУЧЕНИЯ
}

\author{
И.Н. Миронова \\ Московский гуманитарный университет
}

\begin{abstract}
Аннотация: В статье раскрывается сущность предметно-языкового интегрированного подхода в обучении CLIL (Content and Language Integrated Learning). Проанализированы основные принциипы и названы причины внедрения CLIL в образовательный прочесс выстей школьы для интенсификации профессиональной подготовки студентов вуза.
\end{abstract}

Ключевые слова: CLIL, предметно-языковое интегрированное обучение, принципы, методология

\section{BASIC PRINCIPLES AND REASONS FOR THE CONTENT AND LANGUAGE INTEGRATED LEARNING IMPLEMENTATION}

\author{
I.N. Mironova \\ Moscow University for the Humanities
}

\begin{abstract}
The article reveals the essence of the content and language integrated approach in teaching. The main CLIL principles and reasons for introduction into the educational process have been named and analyzed for the students 'professional training intensification.
\end{abstract}

Keywords: CLIL, content and language integrated learning, principles, methodology

Одним из эффективных подходов к обучению студентов предметному знанию на иностранном языке в Европе является предметно-языковое интегрированное обучение (Content and Language Integrated Learning, CLIL), далее - CLIL. Предметно-языковое интегрированное обучение - это современный образовательный подход с двойным фокусом, при котором иностранный язык используется для изучения и преподавания, как языка, так и содержания. Т.е. в процессе преподавания и обучения внимание уделяется не только содержанию, но и не только языку. Они переплетены, даже если больший акцент делается на тот или иной аспект в определенное время. В 1994 г. был принят термин «Предметно-языковое интегрированное обучение» для описания и дальнейшей разработки передового опыта европейских школ, где преподавание и обучение проводилось на дополнительном языке (Coyle, Hood, Marsh, 2010: 3) .

Можно сказать, что первой известной программе CLIL примерно 5000 лет! Именно тогда в Месопотамии (нынешняя территория Ирака) аккадцы, покорившие шумеров, хотели выучить местный язык. Шумерский был использован в качестве средства обучения, чтобы преподавать аккадцам несколько предметов одновременно, включая теологию, ботанику и зоологию. Если шумерские инструкторы были верны основным принципам CLIL, они поддерживали изучение шумерского языка, 
a также изучение содержания в богословии, ботанике и зоологии (Mehisto, Marsh, Frigols, 2008: 9).

Использование учебной программы на дополнительном языке было знакомо и римлянам. Это произошло две тысячи лет назад, когда Римская империя расширилась и впитала в себя греческую территорию, а вместе с ней - язык и культуру. Семьи в Риме обучали своих детей греческому языку, чтобы обеспечить доступ не только к языку, но и к социальным и профессиональным возможностям, которые пригодились бы им в будущем. «Этот исторический опыт был воспроизведен во всем мире на протяжении веков и является в настоящее время особенно верным в отношении глобального изучения английского языка» (Coyle, Hood, Marsh, 2010: 2).

«Использование языков для изучения и обучение с использованием языков (формулировка - Дэвида Марша)» упоминается Филом Боллом, автором множества публикаций, посвященных получению знаний на втором и третьем языках, как известный лозунг предметно-языкового интегрированного обучения CLIL. «CLIL может быть мощным средством получения знаний, т.к. соединяет предмет и язык воедино» (Ball, 2012c: 2). Интегрированный предметно-языковой подход должен регламентироваться определёнными принципами: так известные учёные, работающие в сфере полилингвизма и билингвального обучения Питер Мехисто, Дэвид Марш и Мария Фриголс упоминают следующие основные характеристики методологии предметно-языкового интегрированного обучения CLIL. Среди них они выделяют: множественный фокус, обогащённую среду обучения, аутентичность, активное обучение, стратегию «scaffolding» и сотрудничество. Рассмотрим основные характеристики каждого элемента.

1 Множественный фокус реализуется через: (изучение языка при изучении предмета; изучение дисциплины при изучении языка; интеграцию нескольких предметов; организацию обучения через межпредметные темы и проекты).

2 Обогащённая среда обучения включает в себя: (демонстрацию языка и дисциплины на занятии; формирование уверенности у студентов за счёт экспериментов с использованием иностранного языка и содержания предметной дисциплины; доступ к аутентичным учебным материалам).

3. Аутентичность осуществляется через: (максимизацию учета интересов студентов; тенденцию регулярной связи между обучением и жизнью студентов; использование текущих материалов из СМИ и других источников).

4. Стратегия активного обучения реализуется через: (обсуждение значения языка и содержания со студентами и взаимную совместную работу).

5. Стратегия «Scaffolding» - это всесторонняя поддержка студента, способствующая уменьшению когнитивной и лингвистической нагрузки при изучении дисциплины на иностранном языке. Эта стратегия реализуется посредством использования на занятиях языковых клише, терминологического словаря, визуализации материала, снабжения обучающихся большим количеством примеров на иностран- 
ном языке, использования разных стилей обучения, развитием творческого и критического мышления (Зарипова, 2015: 12).

6. Сотрудничество осуществляется через совместное планирование курсов, уроков, тем, разделов программы учителями-лингвистами и предметниками (Mehisto, Marsh, Frigols, 2008: 29).

П. Мехисто, Д. Марш и М. Фриголс далее заявляют, что подход CLIL поддерживает целостное развитие, и его конечная цель состоит в том, чтобы помочь учащимся стать способными и мотивированными, двуязычными или многоязычными, независимыми, успешно приобретающими знания предмета и языка одновременно (Mehisto, Marsh, Frigols, 2008: 30).

Предметно-языковое обучение будет эффективным и успешным, если будет интегрированным. Из самого термина «предметно-языковое интегрированное обучение» следует, что его ключевым методологическим положением является интеграция. При этом интеграция предполагает взаимопроникновение, взаимовлияние. «Интеграция в образовании осуществляется через реализацию междисциплинарных связей. А междисциплинарные связи разрешают противоречие между знаниями различных учебных предметов и необходимостью их синтеза для формирования научных представлений о мире, которые в будущем студенты будут использовать в профессиональной деятельности» (Родионова, 2018: 42).

Предметно-языковое интегрированное обучение регламентируется принципом 4C. Модель 4C - Content, Communication, Cognition, Culture, предложенная профессором Д. Койл предлагает эффективное предметно-языковое интегрированное обучение, как симбиоз содержательного, коммуникативного, когнитивного и культурного компонентов через:

- прогресс в знаниях, навыках и понимании содержания;

- участие в связанной когнитивной обработке;

\section{CLIL is built on 4 pricipals: content, cognition, communication, culture} никативном контексте;

- развитие соответствующих языковых знаний и навыков;

- приобретение глубокого межкультурного сознания (Coyle, Hood, Marsh 2010: 41).

Схематически принцип 4C Д. Койл изобразила в виде пирамиды с тремя вершинами, каждая из которых обозначает один из компонентов данного принципа. Интересно, что компонент Communication (коммуникация)

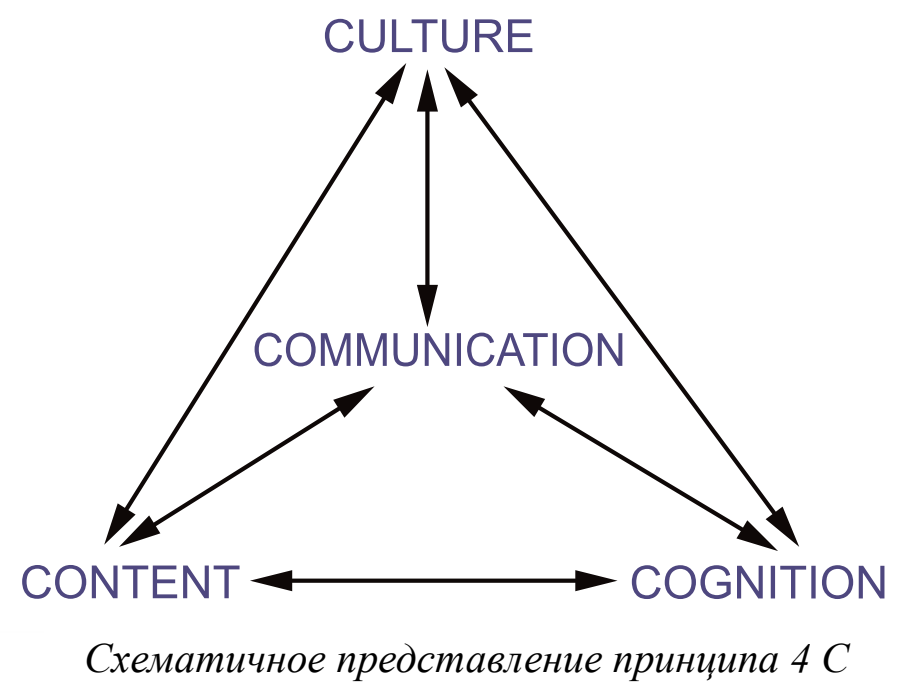


расположен в центре пирамиды, что говорит о том, что остальные компоненты (Content, Cognition, Culture) должны реализовываться через коммуникацию (Сoyle, Hood, Marsh 2010: 36).

П. Мехисто, Д. Марш и М. Фриголс дают свои определения принципам предметно-языкового интегрированного обучения CLIL:

Таблица 1

\begin{tabular}{|c|c|c|c|}
\hline $\begin{array}{l}\text { Cognition } \\
\text { познание }\end{array}$ & $\begin{array}{l}\text { mmunity } \\
\text { общество }\end{array}$ & $\begin{array}{l}\text { ontent } \\
\text { держание }\end{array}$ & $\begin{array}{l}\text { Communication } \\
\text { общение }\end{array}$ \\
\hline $\begin{array}{l}4 \text { Содержание, язы- } \\
\text { ковые и учебные на- } \\
\text { выки формулируются } \\
\text { в сотрудничестве со } \\
\text { студентами; } \\
\text { Обучение основы- } \\
\text { вается на существу- } \\
\text { ющих знаниях, навы- } \\
\text { ках, интересах и опы- } \\
\text { те учащихся; } \\
4 \text { Обучающиеся ана- } \\
\text { лизируют достиже- } \\
\text { ния результатов обу- } \\
\text { чения самостоятель- } \\
\text { но, с другими учени- } \\
\text { ками и с учителем; } \\
4 \text { Студенты синте- } \\
\text { зируют, оценивают и } \\
\text { применяют необходи- } \\
\text { мые знания и навыки, } \\
\text { по нескольким пред- } \\
\text { метам. }\end{array}$ & $\begin{array}{l}4 \text { Студенты чувству- } \\
\text { ют, что участие в об- } \\
\text { разовательном сооб- } \\
\text { ществе обогащает; } \\
\text { чучителя, ученики } \\
\text { и родители являются } \\
\text { партнерами в образо- } \\
\text { вании; } \\
\text { Студенты могут } \\
\text { определить свою роль } \\
\text { в классе в местном и } \\
\text { глобальном контек- } \\
\text { сте. }\end{array}$ & $\begin{array}{l}\text { Содержание чет- } \\
\text { ко связано с сообще- } \\
\text { ством в классе и за } \\
\text { его пределами; } \\
4 \text { Студенты приме- } \\
\text { няют новый контент } \\
\text { и развивают соответ- } \\
\text { ствующие навыки } \\
\text { с помощью экспе- } \\
\text { риментальных дей- } \\
\text { ствий; } \\
4 \text { Содержание явля- } \\
\text { ется существенным, } \\
\text { но не подавляющим; } \\
4 \text { Содержание из раз- } \\
\text { личных предметов ин- } \\
\text { тегрировано } \\
4 \text { Культурный аспект } \\
\text { интегрирован во все } \\
\text { предметы. }\end{array}$ & $\begin{array}{l}4 \text { Учащиеся активно } \\
\text { пользуются правом } \\
\text { участвовать во всех } \\
\text { мероприятиях в клас- } \\
\text { се; } \\
4 \text { Расстановка сто- } \\
\text { лов, дисплеи на сте- } \\
\text { нах классных комнат } \\
\text { и другие доступные } \\
\text { ресурсы используют- } \\
\text { ся для поддержки об- } \\
\text { учения и общения; } \\
4 \text { Языковые / комму- } \\
\text { никативные навыки } \\
\text { развиваются по всем } \\
\text { предметам. }\end{array}$ \\
\hline
\end{tabular}

П. Болл вместо этого дает определение предметно-языкового интегрированного обучения CLIL, состоящее из шести пунктов, основываясь на методологических соображениях:

1. Концептуальная последовательность: одна концепция логически вытекает из другой.

2. Концептуальное направление: критерии оценки понимания материала должны быть основаны на концептуальном и /или процедурном (основанном на навыках) содержании.

3. Язык как средство: язык встречается естественным образом в дискурсивных рамках, связанных с содержанием.

4. Конкретный дизайн задачи: содержание подвергается большей процедурной «разбивке» с обязательной языковой поддержкой (стратегия scaffolding). 
5. Концепция Триединства, основанная на трех элементах образования, гармонично работающих: концептуальное содержание, процессуальное содержание и лингвистический контент.

6. Виды деятельности: четыре вида деятельности лучше всего подходят для практики CLIL - задания для улучшения взаимного общения сверстников, мероприятия по разработке стратегий чтения, мониторинг результатов обучающихся (устных и письменных работ) и деятельность по привлечению более высоких когнитивных навыков (Ball, 2012b: 3).

Далее он заявляет, что конечная цель деятельности CLIL должна выражаться в терминах триады, начиная с концептуальной цели, осуществляемой посредством процессуального решения, при поддержке языка, который возникает в результате определенного дискурса. Ф. Болл утверждает, что в «предметно-языковом интегрированном обучении все три важнейших элемента образования работают в гармонии. Содержание (концептуальное) выучено через процедуру (навыки), которая требует определенного типа конструкций (языка)» (Ball, 2012c: 3).

Для того чтобы полностью понять принципы предметно-языкового интегрированного обучения CLIL, необходимо принять во внимание роль языка в CLIL. К. Келли упоминает, что одна идея, которая является центральной в любом определении подхода CLIL, - это то, что он включает в себя языковую поддержку. «Языковая поддержка относится к стратегиям и методам, которые учителя используют для того, чтобы:

а) выделить основной язык в предметной теме;

б) сделать этот язык доступным для обучающихся данной предметной области (Kelly 2012: 1).

Преподаватели и ученики CLIL нуждаются в знании языка учебного предмета. Этот язык можно разделить на контент-обязательный (content - obligatory language) и контент-совместимый (content - compatible language). Контент-обязательный язык - это язык, необходимый для понимания предмета и обмена идеями (например, картографический словарь по географии). Это словарный запас, грамматические структуры и функциональный язык для конкретных предметов. Это тот язык, который студенты должны знать, чтобы освоить содержание (Mehisto, Marsh, Frigols, 2008: 104).

В классе также используется контент-совместимый язык - повседневный, менее формальный. Контент-совместимый язык выходит на первый план, когда студенты пытаются выразить свои собственные мысли по отношению к изучаемой теме. Следовательно, это часто язык, который действительно интересует студента (Mehisto, Marsh, Frigols 2008: 104).

T. Чедвик делит язык обучающихся на три типа:

- BICS (Basic Interpersonal Communicative Skills) - общая языковая компетенция межличностного общения.

- CL (Classroom Language) - язык, используемый в аудитории. 
- CALP (Cognitive Academic Language Proficiency) - когнитивная языковая компетенция (Chadwick, 2012: 1).

BICS и CALP - две очень важные аббревиатуры, которые канадский лингвист Джим Камминс впервые представил в 1979 г.
BICS
$\mathrm{CL}$
CALP

BICS является социальным языком обучающихся, который они используют в классе, в интернете, в чате с друзьями. Уровень мастерства (BICS) обычно высок по сравнению с (CALP). Так, учителя будут стараться использовать повседневный язык, чтобы представить какое-либо понятие, прежде чем использовать более специализированную терминологию.

$\mathbf{C L}$ - это функциональный язык инструкций в аудитории, студенты знакомятся с этим языком через многократное использование.

CALP - академический язык, он может быть как предметно-ориентированным, так и общеобразовательным. «Этот язык, необходим для понимания и применения новых концепций и идей, это конкретный, необходимый словарный запас определённого предмета. CALP поможет студентам изучить содержание и продемонстрировать свое обучение. Свободное владение BICS не означает знание CALP» (Chadwick, 2012: 3). Все студенты нуждаются в поддержке при освоении академического языка. Таким образом, язык - это то, о чем все учителя должны думать при планировании урока, лекции или занятия. Т. Чедвик утверждает, что самый простой способ сделать это - правильно планировать различные этапы урока, которые позволят достичь поставленных целей и задач. Ученый предлагает следующие этапы планировании языковой поддержки учителя в предметно-языковом интегрированном обучении (Chadwick, 2012:4).

Таблица 2

\title{
1. Vocabulary
}

(словарный запас определенной темы)

- Какой словарный запас необходим студентам для выполнения заданий на уроке?

- Как я могу помочь обучающимся с отбором необходимых лексических единиц?

\section{Functional language}

(Функциональный язык)

- Какие познавательные процессы и навыки творческого мышления используют обучающиеся?

- Какой функциональный язык подходит к этим навыкам?

- Как я буду помогать студентам с языком?

\author{
3. Language skills \\ (Языковые навыки) \\ - Какие языковые навыки используют студенты? \\ - Хочу ли я, чтобы обучающиеся читали, писали, говорили или слушали? \\ - Как это повлияет на всестороннюю поддержку студентов, которую я предоставляю?
}


К. Бентли в свою очередь упоминает о «необходимости учителей предметно-языкового интегрированного обучения CLIL анализировать языковые требования предметных дисциплин, а затем планировать соответствующую языковую поддержку» (Bently, 2010: 37). И с этим нельзя не согласиться, поскольку жанры, с которыми сталкиваются изучающие язык в CLIL, зависят от учебных программ. По предметам науки учащиеся могут выдвинуть гипотезу или описать процедуры, в то время как по таким предметам, как искусство или музыка, обучающиеся читают, дают описания и объяснения.

Д. Койл, П. Худ и Д. Марш (Coyle, Hood, Marsh, 2010: 42) упоминают ключевые значения для интеграции содержания и языка, которые надо учитывать. Первое сфокусировано на потребности учителей определить и обосновать средства интеграции содержания и изучения языка, в какой степени это возможно в зависимости от индивидуальных условий обучения и прогнозируемые результаты обучения. Второе значение зависит от отношений между языковым уровнем обучающихся и их когнитивными способностями.

Ф. Болл утверждает, что предметно-языковое интегрированное обучение CLIL требует от студентов «говорить и писать о понятиях, которые часто находятся за пределами их лингвистического диапазона. Именно эта попытка выразить свое мнение является ключом к языковому развитию в предметно-языковом обучении CLIL» (Ball, 2012d: 1).

\section{Причины введения предметно-языкового интегрированного обучения CLIL}

Более миллиарда человек в мире свободно говорят на нескольких языках, и практически во всём мире способность говорить на двух языках необходима для успешной реализации человека в жизни (Dulay, Burt, Krashen, 1982: 9). Билингвизм $^{1}$ - это реальность для миллионов детей во всем мире. Некоторые изучают несколько языков с раннего детства, другие приобретают дополнительные языки в школе. «Знание более одного языка может открыть двери для многих личных, социальных и экономических возможностей» (Lightbown, Spada 2006: 25). Поскольку английский становится существенным дополнением к любой учебной программе по всему миру, «он движется к положению, когда становится предметом, через который обучаются студенты» (Ball 2012a: 3).

Предметно-языковое интегрированное обучение CLIL является инструментом для обучения и изучения содержания и языка. «Студент желает понять содержание, которое в свою очередь мотивирует его изучать язык. Даже на уроках иностранного языка студенты могут изучить больше, если они не просто изучают язык ради языка, а если используют его для выполнения конкретной задачи» (Mehisto, Marsh, Frigols 2008: 11). Идея использовать язык для того, чтобы познать что-то еще, является центральной идеей CLIL.

Л. Дейл и Р. Таннер утверждают, что «обучающиеся CLIL мотивированы, потому что они испытывают трудности при изучении, как предмета, так и языка. Уча-

${ }^{1}$ Билингви́зм (двуязы́чие < дат. bi - «два» + лат. lingua «язык»): одинаково совершенное владение двумя языками, умение в равной степени использовать их в необходимых условиях общения. 
щиеся CLIL развивают когнитивные способности, ведь их мозг работает усерднее, а теория когнитивного обучения предполагает, что люди помнят информацию более эффективно, если их мозг работает усердно, чтобы выполнить задачу. Учёные также заявляют, что CLIL-обучающиеся получают выгоду от развития коммуникативных навыков, при этом и язык прогрессирует быстреe (Dale, Tanner, 2012:11) .

К. Бентли утверждает, что предметно-языковое интегрированное обучение CLIL стремится:

- познакомить обучающихся с новыми понятиями посредством изучения учебной программы на иностранном языке;

- улучшить успеваемость учащихся по учебным дисциплинам и целевому языку;

- повысить уверенность студентов в изучаемом языке;

- предоставить материалы, которые развивают навыки мышления с самого начала;

- поощрять более тесные связи с ценностями общества и гражданства (Bently, 2010: 6).

Среди распространенных причин введения предметно-языкового интегрированного обучения Д. Койл, П. Худ и Д. Марш называют «подготовку к глобализации, расширение школьных профилей, подготовку к будущему обучению, получение навыков для трудовой жизни, улучшение общей целевой языковой компетенции, развитие навыков устной речи, развитие уверенности в себе, повышение мотивации обучающихся, разработку индивидуальных стратегий обучения, а также - внедрение более широкого культурного контекста» (Coyle, Hood, Marsh, 2010: 17).

CLIL также улучшает качество преподавания дополнительного языка, т.к. использование иностранного языка в качестве средства обучения делает учителя более осведомленным о языковых потребностях студентов. Также необходимость постоянных проверок понимания приводит к высокому уровню общения между учителями и студентами (Там же).

Как говорит Ф. Болл: «Будет ли аббревиатура CLIL существовать через десять лет, вероятно, не имеет значения. Будущее - за компетенциями» (Ball, 2012d: 4). Это подразумевает, что развитие компетенций может произойти в рамках подхода, который ставит на первое место навыки мышления и общения.

Таким образом, CLIL положительно влияет на мотивацию обучающихся по овладению ими предметного содержания. CLIL способствует более глубокому пониманию сути предмета, т.к. занятия требуют широкого применения мыслительных навыков высшего порядка. У студентов формируются фундаментальные знания, включающие в себя понятийный ряд дисциплины, навыки использования коммуникативных технологий и междисциплинарные знания по направлению обучения. Учителя иностранных языков всегда должны смотреть вперед, всегда быть в поиске эффективных путей обучения и изучения языка. Принципы CLIL делают именно это, а значит, стоит поприветствовать внедрение предметно-языкового интегрированного обучения CLIL в классе. 


\section{СПИСОК ЛИТЕРАТУРЫ}

Зарипова, Р.Р., Салехова, Л.Л. (2015) К вопросу о лингвистических и когнитивных преимуществах интегрированного предметно-языкового подхода в обучении (CLIL) //Международный журнал экспериментального образования №8. C. 9-13.

Родионова, Е.В. (2018) Методологические основы предметно-языкового интегрированного обучения высшей школе //Наука и перспективы №4. С. 40-52.

Coyle, D., Hood, P., Marsh, D. (2010) Content and Language Integrated Learning. Cambridge University Press.

Chadwick, T. (2012) Language Awareness in Teaching. A Toolkit for Content and Language Teachers. Cambridge University Press.

Ball, P. (2012 a) What is CLIL? on www.onestopenglish.com

Ball, P. (2012 b) Defining CLIL parametres on www.onestopenglish.com

Ball, P. (2012 c) How do you know if you are practicing CLIL? on www.onestopenglish.com

Ball, P. (2012 d) Activity types in CLIL on www.onestopenglish.com

Ball, P. (2012 f) Integrating CLIL: school management policies, Ministry of Education Czech Republic publications.

Bently, K. (2010) The TKT Course CLIL Module. Cambridge University Press.

Dale, L. and Tanner, R. (2012) CLIL Activities. A Resource for subject and language teacher. Cambridge University Press.

Dulay, H., Burt, M. and Krashen, S.D. (1982) Language Two, New York. Oxford University Press.

Kelly, K. (2012) CLIL for ELT on www.onestopenglish.com

Lightbrown, P.M. and Spada, N. (2006) How Languages are Learned, 3rd Edition in Oxford. Cambridge University Press.

Mehisto, P., Marsh, D. and Frigols, M. J. (2008) Uncovering CLIL. Content and Language Integrated Learning in Bilingual and Multilingual Education, Oxford: Macmillan Education.

Миронова Ирина Николаевна - доцент кафедры иностранных языков Московского гуманитарного университета; аспирант кафедры педагогики и психологии высшей школы Московского гуманитарного университета. Научный руководитель д-р пед. н., проф. В.А. Ситаров. Адрес: 111395, Россия, г. Москва, ул. Юности, д. 5. Тел.: +7 (903) 221-87-83. Эл. адрес: miririna180778@mail.ru.

Mironova Irina Nickolaevna, Associate Professor, Foreign Languages Department; Postgraduate Student, Department of Psychology and Pedagogy of Higher School, Moscow University for the Humanities. Scientific Adviser - V. A. Sitarov, Doctor of Pedagogy, Professor. Postal address: 5, Yunosti St., Moscow, Russian Federation, 111395. Tel.: +7 (903) 221-87-83. E-mail: miririna180778@mail.ru.

\section{Для цитирования:}

Миронова И.Н. Основные принципы и причины внедрения предметно-языкового интегрированного обучения // Научные труды Московского гуманитарного университета. 2020. №4. C. 19-27. DOI: https://www.doi.org/10.17805/trudy.2020.4.3 